\title{
A LIBERDADE NO BRASIL OITOCENTISTA
}

CHALHOUB, Sidney. A força da escravidão: ilegalidade e costume no Brasil oitocentista. São Paulo: Companhia das Letras, 2012. 351 p.

$A$ historiografia sobre a escravidão brasileira sofreu um deslocamento de foco na última década: tornaram-se mais frequentes os estudos acerca da liberdade. A partir das abordagens já clássicas baseadas nos estudos de alforrias ou de ações de liberdade, floresceram trabalhos que enfocam os libertos e investigam suas chances de mobilidade social e espacial, sua cultura política e lutas por direitos, a precariedade material de sua existência e a instabilidade jurídica em que viviam e contra a qual lutavam. Os novos estudos sobre os libertos, seguindo os caminhos abertos pela historiografia da escravidão, reafirmam o protagonismo e reconhecem o impacto de suas ações individuais ou coletivas e também - isso é mais recente - estão mais atentos para as nuances das limitações impostas a essas ações e aos contextos em que as histórias estudadas transcorrem. Já não há mais uma "escravidão", mas muitas, já não há mais "liberdade" absoluta, mas formas de viver em liberdade, de direito e/ou de fato. Esse desdobramento é ainda mais importante se lembrarmos que nos últimos anos a historiografia sobre a escravidão e a liberdade consolidou seu diálogo com áreas como a História do Trabalho, a História do Direito, a nova História Política, a nova História Militar, a História Agrária e a História Atlântica. As contribuições para esses campos são consideráveis e, com esse investimento no tema da liberdade, podem ser ainda mais importantes.

O mais recente livro de Sidney Chalhoub, A força da escravidão, é um ensaio dedicado ao tema da precariedade da liberdade no Brasil oitocentista. Seu argumento é desenvolvido ao longo de dez capítulos e baseado, principalmente, na correspondência da chefia de polícia da Corte 
com diversas autoridades (de juízes de paz e diretor da Casa de Correção ao ministro da Justiça), entre as décadas de 1830 e 1860, e nos livros de entrada da Casa de Detenção da Corte, nas décadas de 1860 e 1870 . Complementam a análise os debates parlamentares, pareceres do Conselho de Estado, processos cíveis, relatórios ministeriais e a legislação, além da literatura de Machado de Assis. O primeiro capítulo, intitulado "O grande medo de 1852", serve de apresentação ao livro e parte da descrição vívida das revoltas ocorridas em várias localidades do interior do Nordeste em reação à implantação do registro civil, no início de 1852. "Ouvindo" os revoltosos através dos relatórios e da correspondência dos presidentes de província com o ministro da Justiça, Chalhoub apura que, entre outros motivos para a revolta, era recorrente o receio de que o registro civil servisse à escravização das pessoas livres pobres, na sua maioria pretas e pardas. Nessa motivação o autor encontra uma conexão com a recente crise em torno da repressão ao tráfico de escravos: em Santo Antão, Pernambuco, o juiz de Direito relatou que o povo estava convencido de que "as disposições do Decreto têm por fim cativar seus filhos, visto que os Ingleses não deixam mais entrar Africanos" (p. 20). Esse receio de escravização que moveu os revoltosos, descartado como "fanatismo" ou "despropósito" pelas autoridades imperiais, é tratado a sério pelo historiador e ancora a construção do argumento, assim descrito: "o assunto desse livro é precisamente a demonstração da confluência histórica desses dois processos: os modos pelos quais a força da escravidão tornava precária a experiência da liberdade de negros livres e pobres no Brasil oitocentista e as lógicas sociais e políticas duma espécie de interdito à própria representação dessa situação" (p. 28). Em outras palavras, são duas questões abordadas em paralelo: a precariedade da liberdade e suas transformações ao longo do século XIX, e os problemas que a falta de aplicação da lei de 1831 suscitou.

Os próximos quatro capítulos tratam, mais ou menos cronologicamente, da "intricada engenharia institucional" montada para silenciar a respeito da entrada de centenas de milhares de africanos contrabandeados entre a proibição do tráfico, em 183031 , e sua efetiva repressão, desencadeada pela lei de 1850 . No capítulo 2, "Escravismo", Chalhoub apresenta as linhas gerais do problema: cerca de $42 \%$ do total estimado do comércio de escravos para o Brasil quatro milhões e oitocentas mil pessoas - teriam chegado na primeira metade do século XIX, sendo que uma parte significativa deles contrabandeados após as proibições do tráfico por tratado internacional ou 
por legislação nacional. Como se articularam o processo de construção do Estado nacional brasileiro e tamanho contrabando? O problema, proposto por Luiz Felipe de Alencastro em 1979, foi abordado do ponto de vista da história política e intelectual pelo recente livro de Tâmis Parron; ${ }^{1}$ no livro de Chalhoub, ele ganha um tratamento de história social. O contexto que enquadra todo o argumento é dado pela conjuntura econômica internacional: o aumento da demanda por matérias primas para as nascentes indústrias e para a massificação do consumo de produtos tropicais (algodão, açúcar, café) gerou uma expansão da escravidão de plantation. Em outras regiões das Américas a escravidão foi gradualmente abolida, mas no sul dos Estados Unidos, em Cuba e no Brasil ela entrou em nova fase, o "segundo escravismo", tradução da expressão cunhada por Dale Tomich. ${ }^{2}$ Em um panorama breve do período anterior a 1831, Chalhoub apresenta as posições de Domingos Alves Branco

1 Luiz Felipe de Alencastro, "La traite négrière et l'unité nationale brésilienne", Revue Française d'Histoire d'Outre-Mer, tomo 66, n. 244-45 (1979), pp. 395-417; e Tâmis Parron, A politica da escravidão no império do Brasil (1826-1865), Rio de Janeiro: Civilização Brasileira, 2009.

2 Dale W. Tomich, Through the Prism of Slavery: Labor, Capital, and World Economy, Lanham: Rowman and Littlefield, 2004.
Muniz Barreto e de José Bonifácio de Andrada e Silva para ilustrar os dilemas em torno da independência e para sugerir que o País teria vivido uma "marcha interrompida da emancipação escrava", bloqueada pelo mergulho no "segundo escravismo" (p. 43).

Nos capítulos seguintes, Chalhoub se concentra em demonstrar a construção da armação política que permitiu silenciar a respeito do direito à liberdade dos africanos trazidos por contrabando declarados livres no primeiro artigo da lei de 1831, e fazer dela uma aplicação muito seletiva. Em paralelo, fazendo extenso uso da correspondência do chefe de polícia da Corte, descreve as artimanhas para a legalização do contrabando e a perseguição sistemática aos africanos libertos, acusados de sedução de escravos ou outros tipos de ameaça à ordem. O capítulo 3, "Sob o domínio da ilegalidade", cobre o começo da década de 1830 e mostra que houve inicialmente intenção de aplicar a lei e que a polícia do Rio de Janeiro adotava na repressão do tráfico a experiência acumulada com o roubo de escravos. A atribuição de responsabilidades pela falta de aplicação da lei recai, nesse capítulo, sobre o judiciário e os agentes da polícia por receberem subornos dos traficantes e fazerem vistas grossas para os desembarques. Eusébio de Queirós, personagem central do livro, a essa altura 
chefe de polícia da Corte, teria pleno conhecimento da existência e do funcionamento do tráfico ilegal.

O capítulo 4, "Modos de silenciar e de não ver", trata da tentativa de revogação da lei de 1831 pelo projeto de lei proposto pelo Marquês de Barbacena ao Senado, em 1837, e de um contexto de "institucionalização" da escravização ilegal dos africanos, no final da década de 1830 e durante a década de 1840 . Sinais dessa política estão, segundo Chalhoub, na ampliação do conceito de africano ladino para incluir gente recém-chegada que falasse qualquer coisa de português e passasse por importada antes da lei, e no afrouxamento dos critérios de prova da propriedade escrava e produção de papéis que davam aparência de legalidade à propriedade ilegal. O texto é pontilhado de evidências quanto a apreensões de africanos novos e casos de dúvidas sobre o estatuto de africanos ou crioulos tidos por escravos fugidos. $\mathrm{Na}$ chefatura de polícia da Corte, em meados da década de 1830 , a presunção era de escravidão e o ônus da prova sobre a liberdade cabia à pessoa considerada escrava. Este seria o maior indício da existência de uma política de precarização da liberdade das pessoas de origem africana, fossem libertas ou nascidas livres, em vigor até a década de 1860, que Chalhoub associa diretamente à conivência com o tráfico ilegal de africanos.
O capítulo 5, "Em 1850, a precisão de calar sobre 1831", revisita o contexto de passagem da lei Eusébio de Queirós, desde a retomada do projeto Barbacena, em 1848. Acrescenta ao já longo debate sobre esse contexto várias provas de que a lei de 1831 esteve no centro das preocupações dos parlamentares, do Conselho de Estado e do gabinete no qual Eusébio de Queirós ocupava agora o cargo de ministro da Justiça. A rejeição do debate público sobre a falta de aplicação da lei teria motivado várias sessões secretas na Câmara e no Senado. Segundo Chalhoub, o êxito na repressão ao tráfico depois de 1850 se deveu à clara distinção feita pelas autoridades imperiais entre os africanos de desembarques recentes, a serem apreendidos e emancipados, e aqueles encontrados em terra cuja data do desembarque não era registrada. Sobre o direito à liberdade desses últimos, o governo se omitiu para evitar confronto com os fazendeiros. A interpretação dos dados do "Transatlantic Slave Trade Database" usados para demonstrar o volume da entrada de africanos nos anos subsequentes a 1850 , aproximadamente 6.900 (p. 127), merece uma correção: desses, pelo menos 5.000 foram apreendidos e emancipados como africanos livres e não acabaram ilegalmente escravizados.

Mais dois capítulos completam o panorama do silêncio acerca do direi- 
to à liberdade dos africanos trazidos por contrabando, agora na fase pós1850. Em "O que os escravos sabiam", Chalhoub tenta apurar a extensão do conhecimento que os escravos tinham do seu direito à liberdade. Suas fontes aqui são variadas: anais do Parlamento, pareceres do Conselho de Estado, correspondência da polícia da Corte. O resultado é um capítulo frágil, em que há apenas um sujeito, o africano Brás, apreendido no início de 1853 após o desembarque do Bracuí, que efetivamente declarou conhecer seu direito à liberdade com base na lei de 1831. ${ }^{3}$ As outras evidências são reflexos do receio dos senhores, parlamentares e governantes. Algumas são significativas, mas caberia explorá-las para além do discurso. ${ }^{4}$ Chalhoub for-

\footnotetext{
3 A estratégia de Brás foi revelada por Martha Abreu, "O caso do Bracuí", in Hebe M. Mattos de Castro e Eduardo Schnoor (orgs.), Resgate: uma janela para $o$ Oitocentos (Rio de Janeiro: TopBooks, 1995), pp. 165-97, e discutida no contexto do conhecimento da lei de 1831 em Beatriz G. Mamigonian, "O direito de ser africano livre: os escravos e as interpretações da lei de 1831", in Silvia H. Lara e Joseli M. N. Mendonça (orgs), Direitos e justiças no Brasil (Campinas: Editora da Unicamp, 2006), pp. 129-60, 142.

4 Uma discussão detalhada da apreensão do Piratinim encontra-se em Beatriz G. Mamigonian, "In the Name of Freedom: Slave Trade Abolition, the Law and the Brazilian Branch of the African Emigration Scheme (Brazil-British West Indies, 1830s1850s), Slavery and Abolition, v. 30, n.1 (2009), pp. 52-9, e a reação do governo e do parlamento é relatada em Parron, $A$ política da escravidão, pp. 314-15.
}

ça a interpretação dos casos de sedução de escravos como se estivessem relacionados ao conhecimento do direito à liberdade, mas não apresenta qualquer evidência nesse sentido.

O capítulo 7, "O que os ingleses viam", visa expor o conhecimento que os funcionários da legação britânica tinham do funcionamento da repressão ao tráfico de escravos. A partir das denúncias feitas por William Christie sobre o tratamento dos africanos livres que ficaram sob a guarda do governo imperial e sem recorrer à extensa documentação britânica disponível, Chalhoub constrói um capítulo fragmentado e impressionista. Nele, repete a interpretação tão corrente na historiografia de que eram praticamente escravos. Aborda também outro tema da pressão britânica: a defesa da liberdade dos africanos ilegalmente escravizados através da denúncia dos anúncios de leilões que traziam suas idades. O capítulo, no entanto, traz evidências contundentes de que a década de 1860 representou um período de grande rebeldia dos africanos livres e de recurso ao judiciário por parte de escravos e africanos livres em busca do reconhecimento do direito à liberdade com base na importação ilegal. Sem dialogar com autores que se debruçaram sobre as ações de liberdade baseadas na lei de 1831 abertas nas décadas de 1860 a 1880, Chalhoub conclui peremptoriamente que o judiciário cedeu à razão de Estado e 
continuou a negar aos africanos contrabandeados e seus descendentes o seu direito à liberdade e a sustentar a ficção de legalidade de boa parte da propriedade escrava existente no país (p. 208).

Na realidade, a vida dos senhores e do governo teria sido mais fácil se tivesse sido assim, mas não foi; prova disso é o grande debate ocorrido a respeito da validade da Lei de 1831 em 1883. ${ }^{5}$ Mas o que os ingleses tinham a ver com isso?

Os dois capítulos que sustentam o argumento da precariedade da liberdade são mais consistentes. Em "Que se cumpra a lei”, Chalhoub desenvolve o tema da aplicação do artigo $7^{\circ}$ da lei de 1831 , que proibia o desembarque de libertos no país. Ele demonstra que Eusébio de Queirós formulou, já em 1834, uma interpretação ampliada da lei, que incluía “todos os estrangeiros de cor", supostamente incluindo africanos, nascidos livres ou não, e ainda pessoas de origem africana de outras partes das Américas. O capítulo acompanha vários casos de pessoas que chegavam ao Rio e precisavam provar terem nascido livres, do contrário seriam consideradas libertas e expulsas. Ain-

\footnotetext{
Mamigonian, "O direito de ser africano livre", 151-55; Antônio Joaquim Macedo Soares, "Doutrina: a lei de 1831 está em vigor" [1883], in Campanha jurídica pela libertação dos escravos, 1867-1888, Rio de Janeiro: José Olympio, 1938, pp. 29-85.
}

da em 1868, o Conselho de Estado expandiu a compreensão dos "libertos" da lei para incluir todos os nãoescravos. As evidências arroladas buscam demonstrar que houve um deslizamento na política imperial da discriminação por estatuto para a discriminação por cor ou origem, reforçando argumento defendido por Wlamyra Albuquerque. ${ }^{6}$

O capítulo 9, "Liberdade precária”, é o que tem a argumentação mais cuidadosa e estruturada em forma de demonstração. Baseia-se novamente na correspondência da polícia da Corte com diversas autoridades, agora complementada por um extenso levantamento de mais de oito mil entradas de presos nos livros da Casa de Detenção, das décadas de 1860 e 1870. Aqui, Sidney Chalhoub tem o nó do seu argumento sobre a precariedade da liberdade: filtrando apenas as prisões por "suspeita de ser escravo" ou "suspeita de estar fugido", vêse que, na década de 1860 , os registros do preso cujo estatuto estava em dúvida eram feitos nos livros de escravos e na década de 1870 passaram para os livros das pessoas livres. Disso ele conclui que a presunção de liberdade agora se impunha sobre a política de considerar escravo qualquer negro até que provasse seu di-

\footnotetext{
Wlamyra Ribeiro de Albuquerque, O jogo da dissimulação: abolição e cidadania negra no Brasil, São Paulo: Companhia das Letras, 2009.
} 
reito à liberdade. No estilo que consagrou o autor de Visóes da Liberdade, o capítulo acompanha histórias de pessoas que viveram no limbo entre a escravidão e a liberdade, por incerteza quanto ao seu estatuto. Uma grande seção é dedicada à política imperial a respeito do leilão dos "bens do evento" (termo oitocentista para propriedade sem dono), que acabou por atingir centenas, talvez milhares de pessoas presas como se fossem escravas, mas nunca reclamadas por algum senhor. Na década de 1830 , alguém que passasse seis meses na prisão sem que o senhor viesse buscar era levado a leilão; um decreto de 1842 diminuía o prazo de espera para sessenta dias. A política só mudou depois da lei de 1871, quando efetivamente quem não houvesse sido matriculado como escravo deveria ser considerado livre. Sidney Chalhoub pinça da documentação policial muitos casos de erro de identificação de gente que era liberta e não podia provar sua liberdade e acabou sendo leiloada como escrava (pp. 245-247). A essa forma de precariedade da liberdade se somam outras, como a incerteza do estatuto dos escravos alforriados condicionalmente, frequentemente ameaçados de reescravização; roubo e escravização ilegal de crianças de cor e de crioulos; e casos do interior do Brasil que acabaram aparecendo na Corte, um justamente de Pau d'Alho, Pernambuco, de 1865, e outro da fronteira do Rio Grande do Sul com o Uruguai. Segundo o argumento de Chalhoub, a liberdade teria se precarizado entre as décadas de 1830 e 1860 em virtude da "força da escravidão" - a grande articulação entre proprietários de terra e de escravos, parlamentares, magistrados, conselheiros imperiais e ocupantes de cargos do executivo imperial para silenciar sobre o direito à liberdade dos africanos trazidos por contrabando que, ao virar política de governo, lançou uma sombra sobre a vida de todas as pessoas de origem africana e seus descendentes, fossem escravos, libertos ou livres.

A força da escravidão é um livro politicamente engajado. De escrita cuidadosa e leitura fluida, busca levar a um público amplo o tema da discriminação racial no Brasil oitocentista e assim contribuir para os debates acerca da política de identidade no Brasil contemporâneo. Essa é a força e fraqueza da obra, pois ao mesmo tempo em que possui uma linguagem acessível e uma estrutura ensaística, evita alguns debates recentes da historiografia.

Um dos eixos do livro, o tema da aplicação seletiva da lei de 7 de novembro de 1831, tem atraído a atenção de um crescente número de historiadores. Argumento em ações de liberdade, especialmente nas décadas de 1870 e 1880, a invocação à lei de 1831 para provar escravização ilegal 
era o que havia de mais radical no abolicionismo. ${ }^{7}$ Os testemunhos dos africanos ilegalmente escravizados contidos nessas ações serviram como evidência do funcionamento do tráfico ilegal, contribuindo para um ramo fértil da historiografia. ${ }^{8}$ Mais recen-

7 Elciene Azevedo, Orfeu de carapinha: a trajetória de Luiz Gama na imperial cidade de São Paulo, Campinas: Editora da Unicamp, 1999; Elciene Azevedo, $O$ direito dos escravos: lutas jurídicas e abolicionismo em São Paulo, Campinas: Editora da Unicamp, 2010; Argemiro Eloy Gurgel, "A lei de 7 de novembro de 1831 e as ações cíveis de liberdade na cidade de Valença (1870-1888)" (Dissertação de Mestrado em História, UFRJ, 2004); Maria Angélica Zubarán, "Sepultados no silêncio: a lei de 1831 e as ações de liberdade nas fronteiras meridionais do Brasil (1850-1880)", Estudos Afro-Asiáticos, n. 29 (2009), pp. 28199; Ricardo T. C. Silva, "O resgate da lei de 7 de novembro de 1831 no contexto do abolicionismo baiano", Estudos Afro-Asiáticos, n. 29 (2007), pp. 301-40.

8 Vinicius P. de Oliveira, De Manoel Congo a Manoel de Paula: um africano ladino em terras meridionais, Porto Alegre: EST Edições, 2006; Ricardo Tadeu Caíres Silva, "Memórias do tráfico ilegal de escravos nas ações de liberdade: Bahia, 1885-1888", Afro-Ásia, n. 35 (2007), pp. 37-82; João José Reis, Flávio dos Santos Gomes e Marcus J. M. de Carvalho, O Alufá Rufino: tráfico, escravidão e liberdade no Atlântico negro (c. 1822-c. 1853), São Paulo: Companhia das Letras, 2010; Marcus J. M. Carvalho, "A repressão ao tráfico atlântico de escravos e a disputa partidária nas províncias: os ataques aos desembarques em Pernambuco durante o governo praieiro, 1845-1848", Tempo, n. 27 (2009), pp. 151-67; Paulo C. Oliveira de Jesus, "Notícias de um pequeno traficante ilegal na Bahia (1837-1855)", trabalho apresentado no XXVI Simpósio Nacional de História, São Paulo, 2011. temente, a investigação das implicações diplomáticas da escravização ilegal dos africanos importados por contrabando ou de pessoas livres de cor vindas de fora do Império (do Uruguai ou da Argentina, por exemplo) vem demonstrando outras motivações para a dinâmica política de repressão ao tráfico, em 1850, ou a adoção da política de abolição gradual, em 1871. ${ }^{9} \mathrm{O}$ livro de Chalhoub

9 Para os conflitos suscitados com o Uruguai na fronteira sul, ver Rafael Peter de Lima, "A nefanda pirataria de carne humana: escravizações ilegais e relações políticas na fronteira do Brasil meridional (1851-1868)" (Dissertação de Mestrado em História, UFRGS, 2010); Jonatas Marques Caratti, “O solo da liberdade: as trajetórias da preta Faustina e do pardo Anacleto pela fronteira rio-grandense no contexto das leis abolicionistas uruguaias (1842-1862)" (Dissertação de Mestrado em História, UNISINOS, 2010); Keila Grinberg, "Slavery, Manumission and the Law in NineteenthCentury Brazil: Reflections on the Law of 1831 and the 'Principle of Libert' on the Southern Frontier of the Brazilian Empire", European Review of History / Revue Européenne d'Histoire, n. 16 (2009), pp. 401-11; Keila Grinberg e Rachel da Silveira Caé, "Escravidão, fronteira e relações diplomáticas Brasil-Uruguai, 1840-1860”, Africana Studia, n. 14 (2010), pp. 275-85; para uma nova perspectiva dos conflitos diplomáticos com a Inglaterra acerca da escravidão, ver Beatriz G. Mamigonian, "A GrãBretanha, o Brasil e a liberdade dos africanos na crise da abolição do tráfico atlântico de escravos (1848-1851)", in Daniel Aarão Reis e Denis Rolland (orgs.), Intelectuais e modernidades (Rio de Janeiro: Editora da FGV, 2010), pp. 13-29; Beatriz G. Mamigonian, "O Estado nacional e a instabilidade da propriedade escrava: a Lei de 1831 e a matrícula dos escravos de 1872", Almanack, n. 2 (2011), pp. 20-37. 
se insere, portanto, na historiografia que vem relendo os nexos entre a manutenção da escravidão e a construção do Estado nacional brasileiro no século XIX.

A precariedade da liberdade é o tema central do livro. O termo "precariedade" é adotado ao longo do livro com o sentido de instabilidade jurídica e não de condição de vida ou de trabalho. Sidney Chalhoub procura sensibilizar os leitores para os dramas nas histórias de escravização de pessoas livres e de reescravização de libertos. Servem como denúncia da operação do Estado em defesa dos interesses escravistas frequentemente à revelia da legislação e são também dolorosas demonstrações de discriminação correntes na sociedade brasileira oitocentista.

O leitor familiarizado com os temas oitocentistas observará algumas lacunas no argumento. Ao abordar a questão da liberdade, Chalhoub optou por um recorte quase cirúrgico, próximo da fronteira com a escravidão: detalhar o funcionamento dos mecanismos de (re)escravização de pessoas livres de origem africana. A documentação de polícia da Corte, espinha dorsal para o argumento do autor, impõe certos limites à generalização. $\mathrm{O}$ primeiro é geográfico: a polícia da Corte velava sobre a maior cidade escravista das Américas e o maior porto do tráfico ilegal do Atlântico, mas tinha atribuições específicas relacionadas à manutenção da ordem apenas naquele território, cabendo as diretrizes nacionais ao ministério da Justiça. O segundo é social: a amostragem de pessoas livres que caíam nas malhas da polícia da Corte por suspeita de serem escravas é distorcida em relação ao conjunto e esconde uma significativa camada de livres de cor e libertos que não sofria tão de perto essa ameaça, por terem ascendido na hierarquia da sociedade escravista. Os mecanismos desta hierarquização entre as pessoas de origem africana, fundamental para o entendimento dos critérios da polícia, só poderiam ser apreendidos levando-se em conta outras variáveis, que não foram consideradas.

O cenário mais amplo de discussão da liberdade das pessoas livres pobres abre-se para outra precariedade: a das suas condições de vida e trabalho, e coloca os sujeitos de origem africana descritos no livro entre outros grupos da população livre, como índios, soldados, marinheiros, viúvas, crianças menores etc. ${ }^{10}$ Ao evitar situar a precariedade jurídica de que trata no livro no universo maior das experiências na liberdade, Chalhoub deixou de conversar com os inovadores trabalhos recentes acerca da população livre pobre e suas aspira-

\footnotetext{
${ }^{10}$ Para um primeiro tratamento da precariedade da liberdade nesse sentido, ver Henrique Espada Lima, "Sob o domínio da precariedade: escravidão e os significados da liberdade de trabalho no século XIX", Topoi, v. 6, n.11 (2005), pp. 289-325.
} 
ções de dignidade, respeitabilidade mobilidade social ascendente e apagamento da cor. ${ }^{11} \mathrm{O}$ tema da cidadania, tão importante para as pessoas livres de cor no Oitocentos, e chave para a compreensão da política de restrição da mobilidade social e física dos africanos, está surpreendentemente ausente do livro. ${ }^{12}$

Chalhoub assume - sem o dizer que a política conservadora das décadas de 1830 a 1860 é a tradução nacio-

11 Peter M. Beattie, The Tribute of Blood: Army, Honor, Race, and Nation in Brazil 1864-1945, Durham: Duke University Press, 2001; Mônica Duarte Dantas (org.), Revolta, motins, revoluções: homens livres pobres no Brasil do século XIX (São Paulo: Alameda/USP/CAPES, 2011); Roberto Guedes, Egressos do cativeiro: trabalho, familia, aliança e mobilidade Social (Porto Feliz, São Paulo, c.1798-c.1850), Rio de Janeiro: Mauad/FAPERJ, 2008; Zephyr L. Frank, Dutra's World: Wealth and Family in Nineteenth Century Rio de Janeiro, Albuquerque: University of New Mexico Press, 2004; Marcelo MacCord, Artifices da cidadania: mutualismo, educação e trabalho no Recife oitocentista, Campinas: FAPESP/ Editora da Unicamp, 2012.

12 Manuela Carneiro da Cunha, Negros, estrangeiros: os escravos libertos e sua volta à África, São Paulo: Brasiliense, 1985; Hebe Maria Mattos, Das cores do silêncio: os significados da liberdade no sudeste escravista, Brasil, século XIX, Rio de Janeiro: Nova Fronteira, 1998; Keila Grinberg, O fiador dos brasileiros: cidadania, escravidão e direito civil no tempo de Antonio Pereira Rebouças, Rio de Janeiro: Civilização Brasileira, 2002; Gladys Sabina Ribeiro, A liberdade em construção: identidade nacional e conflitos antilusitanos no Primeiro Reinado, Rio de Janeiro: Relume Dumará, 2002. nal do "segundo escravismo". Ora, por um lado, haveria que discutir os mecanismos da aplicação de tal política em regiões do país onde não houve a tal expansão da agricultura exportadora. Por outro, resta a pergunta: se o chamado "segundo escravismo" está associado à montagem do esquema de defesa da escravização ilegal, o que explica a desmontagem do esquema?

A falta de aplicação da lei de 1831 teve enorme impacto sobre as vidas dos africanos importados durante o período do tráfico ilegal e sobre os de seus filhos e netos, é certo, mas não explica totalmente a precariedade da liberdade no Brasil oitocentista, como Chalhoub dá a entender. Precariedade, no sentido de instabilidade jurídica, nos casos de escravização de pessoas livres, de alforria condicional ou promessa de alforria em testamento, não chegava a ser novidade do período da centralização monárquica. Alguns casos de escravização de pessoas livres relatados por Marcus Carvalho e citados por Chalhoub remontam ao período anterior à lei de $1831 .{ }^{13}$ Fernanda Domingos Pinheiro relata uma variedade de casos de reescravização em Mariana no século XVIII. ${ }^{14}$

13 Marcus J. M. Carvalho, Liberdade: rotinas e rupturas do escravismo, Recife, 1822-1850, Recife: Editora da UFPE, 1998 , p. 242-44.

14 Fernanda A. Domingos Pinheiro, "A precariedade da liberdade: experiências de libertos em Mariana, século XVIII", Anais do $4^{\circ}$ Encontro Escravidão e Liberdade no Brasil Meridional, Curitiba, 2009. 
E antes mesmo de 1831, a proibição do tráfico ao norte do Equador, em 1815, tinha jogado na ilegalidade o fluxo entre a Costa da Mina e a Bahia, gerando algumas dezenas de milhares de africanos escravizados ilegalmente e forçando, da parte dos senhores e autoridades baianas, um silenciamento a respeito do direito à liberdade. A existência de diferentes mecanismos de escravização de pessoas livres não necessariamente relacionados com a precarização motivada pela conivência com o tráfico ilegal pode explicar o medo de escravização de pessoas livres no interior do Nordeste em 1852 , região bem menos afetada pelo contrabando de africanos do que o interior das províncias do Rio, Minas ou São Paulo.

Se a precariedade da liberdade não pode ser atribuída apenas à "força da escravidão" construída durante a centralização conservadora, não podemos deixar de reconhecer que a escravização ilegal dos africanos trazidos por contrabando depois da proibição do tráfico é elemento fundante da história do Brasil, trouxe consequências que mal começamos a identificar e implica a todos os brasileiros. É esse o tom do capítulo que fecha o livro, "Machado de Assis (re- mate)", em que Chalhoub invoca $\mathrm{Me}$ mórias Póstumas de Brás Cubas para demonstrar que o romance machadiano, publicado originalmente em 1880 e considerado obra-prima da literatura nacional, é construído sobre uma

homologia entre o tema do adultério de Brás e Virgília e o problema do contrabando de africanos e da propriedade escrava ilegal no Brasil imperial (p. 292).

Machado lidava com o conhecimento que o público tinha da ilegalidade da escravidão que, como um caso de adultério, suscitava reações. Chalhoub extrai de uma fala de Brás Cubas no romance a reflexão que lhe serve de conclusão moral:

Outrossim, afeiçoei-me à contemplação da injustiça humana, inclinei-me a atenuá-la, a explicá-la, a classificála por partes, a entendê-la, não segundo um padrão rígido, mas ao sabor das circunstâncias e lugares (cap. XI) (p. 296).

O personagem simboliza todos aqueles cientes da injustiça, mas de fato tão enredados nela que incapazes de qualquer movimento que não seja o da tentativa de compreensão. Talvez estejamos nós, como país, ensaiando ultrapassar esse estágio apenas agora.

Beatriz Gallotti Mamigonian bgmamigo@gmail.com Universidade Federal de Santa Catarina 
